\title{
Bevacizumab plus Irinotecan-Based Regimens in the Treatment of Metastatic Colorectal Cancer
}

\author{
Volker Heinemann ${ }^{a}$ Paulo M. Hoff ${ }^{b}$ \\ a Department of Medical Oncology, University of Munich, Campus Grosshadern, Munich, Germany;

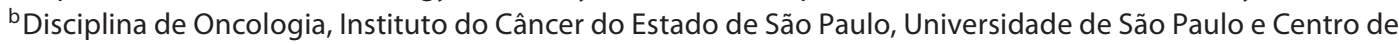 \\ Oncologia, Hospital Sirio Libanes, São Paulo, Brazil
}

\section{Key Words}

Bevacizumab · Chemotherapy - Efficacy · Metastatic

colorectal cancer $\cdot$ Irinotecan $\cdot$ Safety

\begin{abstract}
Objectives: Bevacizumab is a monoclonal antibody that directly inhibits vascular endothelial growth factor, a key regulator of angiogenesis. Bevacizumab significantly improves progression-free and/or overall survival in metastatic colorectal cancer in combination with standard chemotherapy. This review describes the evolution of irinotecan-based regimens for metastatic colorectal cancer and evaluates the addition of bevacizumab to these regimens. Methods: Literature searches from large publication databases (PubMed, ASCO, ASCO GI, ESMO) were performed to capture key data relevant to bevacizumab, irinotecan, and the treatment of colorectal cancer. Results: Data from numerous large, multinational studies support the addition of bevacizumab to irinotecan-containing chemotherapy regimens for further improvement in patient outcomes. In a randomized, placebo-controlled trial, addition of bevacizumab to irinotecan significantly improved progression-free survival, overall survival and response rate in patients with metastatic colorectal cancer, and these results are supported by a number of other clinical trials and observational studies. Furthermore, the
\end{abstract}

addition of bevacizumab to irinotecan improves outcomes regardless of K-ras mutational status. Bevacizumab has a well-established safety profile and the toxicities associated with its use are usually mild in severity and easily manageable. Conclusions: Addition of bevacizumab to irinotecancontaining regimens is an effective therapy option for the treatment of metastatic colorectal cancer.

Copyright $\odot 2010$ S. Karger AG, Basel

\section{Introduction}

In Europe, there was an estimated 412,900 new cases of colorectal cancer (CRC) diagnosed in 2006, with approximately 207,400 CRC-related deaths, representing the second highest cancer mortality rate [1]. Approximately $25 \%$ of CRC patients present with synchronous metastatic disease at first diagnosis, while an additional 40-50\% develop metastases during the course of their disease [2].

Conflict of Interest: Prof. Heinemann has been a consultant and has participated in advisory boards for Roche; he has received research funding from Roche and Pfizer. Prof. Hoff has been a consultant and participated in advisory boards for Roche, he is a member of the ASCO Educational Committee and has received research funding and performed contracted research for Pfizer.

\section{KARGER}

Fax +41613061234 E-Mail karger@karger.ch www.karger.com
(C) 2010 S. Karger AG, Basel $0030-2414 / 10 / 0792-0118 \$ 26.00 / 0$

Accessible online at:

www.karger.com/ocl
Volker Heinemann

Department of Medical Oncology, University of Munich, Campus Grosshadern DE-81377 Munich (Germany)

Tel. +49897095 2250, Fax +49 8970952257

E-Mail volker.heinemann@med.uni-muenchen.de 
Irinotecan has been available for the treatment of metastatic CRC (mCRC) since 1994 in the USA and 1995 in Europe. Irinotecan monotherapy was initially established as a standard second-line therapy for mCRC after two large randomized phase III trials demonstrated that it improved overall survival (OS) compared with 5-fluorouracil (5-FU)/leucovorin (LV) or best supportive care $[3,4]$. Subsequent phase III trials confirmed its efficacy as a first-line therapy in combination with bolus 5-FU/LV (IFL) or infusional 5-FU/LV (FOLFIRI) $[5,6]$.

An alternative to $5-\mathrm{FU} / \mathrm{LV}$ is the $5-\mathrm{FU}$ prodrug capecitabine $\left(\mathrm{Xeloda}^{\circledR}\right)$, an oral fluoropyrimidine that is activated to 5-FU by thymidine phosphorylase primarily within the tumor cell. Clinical trials have shown that capecitabine has a comparable efficacy and safety profile to 5-FU in patients with mCRC [7-9]. The efficacy and tolerability of capecitabine in combination with irinotecan (CAPIRI) in first-line mCRC have been evaluated in several randomized controlled studies, with conflicting findings with regard to toxicity, despite using similar regimens. In the Bolus, Infusional, or Capecitabine with Camptosar-Celecoxib (BICC-C) study, CAPIRI and FOLFIRI were not significantly different in terms of OS, but progression-free survival (PFS) was superior with FOLFIRI (7.6 vs. 5.8 months; $\mathrm{p}=0.015$ ) [10]. Notably, higher rates of severe vomiting, diarrhea, and dehydration were observed in the CAPIRI group than in the FOLFIRI group. However, in the large CAIRO study, CAPIRI was associated with a PFS of 8.0 months with an acceptable toxicity profile [11]. In more recent studies, dose adjustments within newer CAPIRI regimens have led to improved tolerability of this drug combination without loss of efficacy $[12,13]$.

Although the addition of irinotecan to 5-FU- or capecitabine-based chemotherapy regimens extended patient survival, improvements in outcomes achieved with chemotherapy reached a therapeutic plateau, warranting the need for alternative/additional active agents.

The need for more active and better tolerated therapies in addition to the increased knowledge of the complex process of tumor biology and evolution has driven the research and development of novel agents. Bevacizumab (Avastin ${ }^{\circledR}$ ) is a humanized monoclonal antibody binding to vascular endothelial growth factor, a key mediator of angiogenesis.

Phase III clinical trials have demonstrated that the addition of bevacizumab to standard chemotherapy regimens, such as those containing irinotecan or oxaliplatin, significantly improves PFS compared with chemotherapy alone in patients with mCRC $[14,15]$. Furthermore, a recent meta-analysis of five randomized studies of bevacizumab incorporating a total of 3,103 patients with mCRC demonstrated that OS as well as PFS and overall response rate (ORR) were increased significantly with the addition of bevacizumab to chemotherapy (PFS, hazard ratio $(\mathrm{HR})=0.66, \mathrm{p}<0.01$; OS, $\mathrm{HR}=0.77, \mathrm{p}<0.01$; ORR, relative risk $=1.5, \mathrm{p}=0.021)$ [16].

Following US Food and Drug Administration (FDA) approval in 2004 as first-line therapy for mCRC in combination with IFL, bevacizumab has recently received a label extension in Europe and is now registered for combination with all standard fluoropyrimidine-based chemotherapies as first and later lines of therapy in patients with mCRC.

The objective of this review is to describe the evolution of irinotecan-based regimens for mCRC and consider the impact on efficacy and tolerability of adding bevacizumab to these regimens.

\section{Methods}

Literature searches from large publication databases (PubMed, ASCO, ASCO GI, ESMO) were performed to capture key data relevant to bevacizumab, irinotecan, and the treatment of CRC.

\section{Clinical Efficacy of Bevacizumab plus Irinotecan}

The efficacy of bevacizumab combined with irinotecan-based chemotherapies has been evaluated in a number of key clinical trials [12, 14-31]. Tables 1 and 2 highlight the key efficacy data from these studies; all methodology has been previously reported and is not reiterated within this review.

\section{Bevacizumab plus IFL}

The marked improvement in survival reported when irinotecan was combined with bolus 5-FU/LV [6] led to this regimen (IFL) becoming the first-line standard of care in the USA in patients with mCRC. It was, therefore, notable that the pivotal phase III study of bevacizumab in mCRC (AVF2107g) showed that the addition of bevacizumab to IFL significantly increased OS by 4.7 months compared with IFL plus placebo (20.3 vs. 15.6 months, respectively, $\mathrm{HR}=0.66 ; \mathrm{p}<0.001$ ) [14]. Likewise, compared with IFL plus placebo, bevacizumab in combination with irinotecan was associated with significantly longer PFS (median 10.6 vs. 6.2 months, respectively; $\mathrm{HR}=0.54$; 
Table 1. Efficacy results from clinical trials evaluating bevacizumab combined with irinotecan-based, first-line chemotherapy regimens

\begin{tabular}{|c|c|c|c|c|c|c|c|}
\hline Study & Phase & $\mathrm{n}$ & Regimen & Primary endpoint & OS, months & PFS, months & ORR, \% \\
\hline AVF2107g [14] & III & 813 & $\begin{array}{l}\text { IFL + BEV } \\
\text { vs. IFL + placebo }\end{array}$ & OS & $\begin{array}{l}20.3 \text { vs. } 15.6 \\
(H R=0.66 ; p<0.001)\end{array}$ & $\begin{array}{l}10.6 \text { vs. } 6.2 \\
(\mathrm{HR}=0.54 ; \mathrm{p}<0.001)\end{array}$ & $\begin{array}{l}44.8 \text { vs. } 34.8 \\
(p=0.004)\end{array}$ \\
\hline MD Anderson [17] & II & 43 & FOLFIRI + BEV & PFS & - & 12.5 & 60 \\
\hline BICC-C $[10,18]$ & II & 117 & $\begin{array}{l}\text { FOLFIRI + BEV } \\
\text { vs. mIFL + BEV }\end{array}$ & PFS & $\begin{array}{l}28.0 \text { vs. } 19.2 \\
(\text { HR for death = } 1.79 \\
p=0.037)\end{array}$ & 11.2 vs. $8.3(\mathrm{p}=0.28)$ & $\begin{array}{l}57.9 \text { vs. } 53.3 \\
\text { NS }\end{array}$ \\
\hline AIO 0604 [12] & II & 247 & $\begin{array}{l}\text { CAPOX + BEV } \\
\text { vs. CAPIRI + BEV }\end{array}$ & PFS & $\begin{array}{l}26.7 \text { vs. not reached } \\
(\mathrm{p}=0.55)\end{array}$ & 10.4 vs. $12.1(\mathrm{p}=0.27)$ & 53 vs. 55 \\
\hline $\begin{array}{l}\text { GONO- } \\
\text { FOLFOXIRI [19] }\end{array}$ & II & 57 & FOLFOXIRI + BEV & $\begin{array}{l}\% \text { patients } \\
\text { progression- } \\
\text { free at } 10 \text { months }\end{array}$ & - & - & 75 \\
\hline PACCE [20] & III & 230 & $\begin{array}{l}\text { IRI + BEV + pmab } \\
\text { vs. IRI + BEV }\end{array}$ & PFS & $\begin{array}{l}20.7 \text { vs. } 20.5(\mathrm{HR}=1.42 \text {, } \\
95 \% \text { CI: } 0.77-2.62)\end{array}$ & $\begin{array}{l}10.1 \text { vs. } 11.7(\mathrm{HR}=1.19 \\
95 \% \text { CI: } 0.79-1.79)\end{array}$ & $\begin{array}{l}43 \text { vs. } 40(\mathrm{HR}=1.11 \text {, } \\
95 \% \text { CI: } 0.65-1.90)\end{array}$ \\
\hline Ardalan et al. [21] & II & 22 & $\mathrm{IFL}+\mathrm{BEV}$ & OS & not reached & 13.1 (lower 95\% CI: 8.4) & $\begin{array}{l}66.7 \text { (95\% CI: } 43.0- \\
85.4)\end{array}$ \\
\hline Vieitez et al. [22] & II & 85 & CAPIRI + BEV & - & 22.3 (95\% CI: 17.4-27.2) & 15.0 (95\% CI: $11.3-18.7)$ & 65 (95\% CI: 58-72) \\
\hline Welch et al. [23] & II & 50 & CAPIRI + BEV & PFS & - & $\begin{array}{l}11.1 \text { (lower 95\% CI:9.2; } \\
\mathrm{n}=21 \text { ) }\end{array}$ & $40 \%$ \\
\hline ACCORD [13] & II & 145 & $\begin{array}{l}\text { FOLFIRI + BEV } \\
\text { vs. CAPIRI + BEV }\end{array}$ & PFS at 6 months & $\begin{array}{l}23.0 \\
23.0\end{array}$ & $\begin{array}{l}9.0 \\
9.0\end{array}$ & $\begin{array}{l}59 \text { (95\% CI: 53-65) } \\
54 \text { (95\% CI: 48-60) }\end{array}$ \\
\hline
\end{tabular}

$\mathrm{BEV}=$ Bevacizumab; $\mathrm{CI}$ = confidence interval; FOLFIRI = 5-FU/LV + irinotecan; IRI = irinotecan; NS = not significant; pmab = panitumumab.

Table 2. Efficacy results from phase IV and observational studies evaluating bevacizumab combined with first-line irinotecan-based chemotherapy regimens

\begin{tabular}{|c|c|c|c|c|c|c|c|}
\hline Study & Phase & $\mathrm{n}$ & Regimen & $\begin{array}{l}\text { Primary } \\
\text { endpoint }\end{array}$ & OS, months & PFS, months & ORR, \% \\
\hline AVIRI [24] & IV & 209 & FOLFIRI + BEV & PFS & 22.2 (95\% CI: 20.5-25.9) & 11.1 (95\% CI: 10.3-12.1) & 53.1 \\
\hline BEAT [25] & Obs. & 503 & FOLFIRI + BEV & safety & 22.7 (95\% CI: 21.7-25.9) & 11.6 (95\% CI: $10.8-12.5)$ & - \\
\hline BRiTE $[26,27]$ & Obs. & 468 & $\begin{array}{l}\text { FOLFIRI + BEV } \\
\text { IFL + BEV }\end{array}$ & safety & $\begin{array}{l}22.9 \text { (95\% CI: } 19.6-27.4) \\
19.9 \text { (95\% CI: } 16.9-23.8)\end{array}$ & $\begin{array}{l}10.8 \text { (95\% CI: 9.7-11.7) } \\
9.0 \text { (95\% CI: 8.2-11.0) }\end{array}$ & - \\
\hline Moehler et al. [28] & II/ Obs. & 46 & CAPIRI + BEV vs. CAPIRI & $\begin{array}{l}\text { response } \\
\text { rate }\end{array}$ & 24 vs. 15 & 12.8 vs. 11.4 & 34.5 vs. 29.4 \\
\hline SICOG [29] & Obs. & 81 & IRIFAFU + BEV & - & - & 14.1 (95\% CI: 9.6-18.6) & 57 (95\% CI: 45-68) \\
\hline Degirmenci et al. [30] & Obs. & 53 & CAPIRI + BEV & - & $20.6 \pm 1.7$ & $12.6 \pm 1.4$ & 43.3 \\
\hline $\begin{array}{l}\text { Garcia Alfonso et al. } \\
\text { [31] }\end{array}$ & Obs. & 43 & CAPIRI + BEV & $\begin{array}{ll}- \\
-\end{array}$ & 19.0 & 10.3 & 62.8 \\
\hline
\end{tabular}

$\mathrm{BEV}$ = Bevacizumab; $\mathrm{CI}$ = confidence interval; FOLFIRI = 5-FU/LV + irinotecan; IRIFAFU = irinotecan, folinic acid, 5-FU; NR = not reported; Obs. = observational study.

$\mathrm{p}<0.001$ ), higher response rate and longer duration of response (table 1). Notably, a retrospective, exploratory analysis demonstrated that the addition of bevacizumab to IFL achieved statistically significant improvements in PFS and OS regardless of objective tumor response [32].
Following disease progression in AVF2107g, patients were unblinded and continued on second-line therapy at the discretion of the study investigator. Oxaliplatin-based regimens were not widely available in the USA at this time; however, of the patients who received oxaliplatin- 
based chemotherapy, OS was longer for those who had originally received IFL plus bevacizumab (median 25.1 months) compared with those who had received IFL plus placebo (22.2 months) [14].

Results from AVF2107g were broadly similar to those with bevacizumab combined with first-line oxaliplatinbased chemotherapy in patients with mCRC [15]. When combined with 5-FU/LV plus oxaliplatin (FOLFOX) or capecitabine plus oxaliplatin (CAPOX), bevacizumab was associated with a significant increase in PFS compared with placebo (from 9.4 vs. 8.0 months, respectively; $\mathrm{p}=0.0023$ ). Median OS was 21.3 months in the bevacizumab group and 19.9 months in the placebo group, but this difference did not reach statistical significance. It should be noted, however, that only 29 and $47 \%$ of bevacizumab and placebo recipients, respectively, were treated until disease progression.

The current data suggest that first-line therapy with bevacizumab plus two active chemotherapeutic agents followed by postprogression therapy with a third active chemotherapy regimen may be an improved management strategy for mCRC. Furthermore, the survival benefit observed with bevacizumab plus IFL may have been more pronounced if second-line oxaliplatin-based regimens had been more widely available and used in this study. This aspect needs to be considered when reviewing recent data reports from randomized trials where the availability of later-line combination therapy has the potential to impact on OS outcome.

\section{Bevacizumab plus FOLFIRI}

Following the demonstrated survival benefit with the addition of bevacizumab to IFL and bevacizumab, it was necessary to assess whether these survival benefits were consistent across different irinotecan-containing regimens to ensure that physicians could select the most appropriate therapies for their patients. This was particularly important, given the preference for IFL in the USA compared with the infusional FOLFIRI regimen in $\mathrm{Eu}-$ rope and in light of data from several studies that indicated the superior efficacy and improved safety of infusional 5-FU compared with bolus 5-FU $[33,34]$.

AVIRI was a phase IV trial initiated at the request of the Swiss regulatory authorities to evaluate the safety and efficacy of bevacizumab in combination with FOLFIRI [24]. The results from this trial indicated that bevacizumab plus FOLFIRI was comparable in efficacy and safety to bevacizumab plus IFL $[14,35]$. Further support for the use of bevacizumab plus FOLFIRI also came from a phase II trial carried out by the MD Anderson Cancer Center, which showed that the addition of bevacizumab to FOLFIRI extended PFS by approximately 4 months compared with historical data for FOLFIRI alone [17, 36].

Controlled evidence for the use of bevacizumab with irinotecan-based regimens has recently been gained from the BICC-C study [10]. This was a phase III trial originally initiated to compare the safety and efficacy of FOLFIRI with modified IFL (mIFL) and CAPIRI in first-line mCRC (period 1). Following FDA approval of bevacizumab, BICC-C was subsequently amended to allow the addition of bevacizumab to mIFL and FOLFIRI (period 2). As previously observed in phase II/III clinical trials, the addition of bevacizumab to chemotherapy in BICC-C resulted in superior patient outcomes compared with results obtained with chemotherapy alone in period 1 of the trial $[10,18]$. Although no significant difference in PFS was detected between patients receiving bevacizumab plus either FOLFIRI or mIFL ( $\mathrm{p}=0.28$; table 1 ), median OS with bevacizumab plus FOLFIRI was 28 months, being significantly longer than for patients receiving bevacizumab plus mIFL (19.2 months; $\mathrm{p}=0.037$ ) [18].

A subgroup analysis evaluated whether these treatment regimens are effective in an older patient population using a cutoff age of 70 years [37]. Due to low patient numbers in the respective subgroups the statistical power was limited, but PFS did not differ significantly between age groups in all treatments combined when bevacizumab was added to FOLFIRI or mIFL. In addition, there was no difference in OS between age groups for the overall cohort or within each treatment arm. Consistent with other recent reports [38-40], these data suggest that age does not affect the degree of benefit achieved from the addition of bevacizumab to chemotherapy and supports consideration of its use in an elderly patient population.

Bevacizumab has also been evaluated in combination with 5-FU/LV plus both oxaliplatin and irinotecan (FOLFOXIRI). Safety data from an ongoing phase II trial suggest that this combination is feasible, with manageable toxicity and no unexpected adverse events [19]. In a further study in 48 patients with mCRC, first-line bevacizumab plus FOLFOXIRI achieved a response rate of $84 \%$ and median PFS and OS durations of 12 months (95\% CI: 2-33 months) and 25 months (95\% CI: 2-34 months), respectively [41]. These data have provided the rationale for a phase III trial directly evaluating bevacizumab plus FOLFIRI compared with bevacizumab plus FOLFOXIRI, which is currently recruiting patients (table 3) [42]. 


\section{Second-Line Bevacizumab plus FOLFIRI}

As a result of the widespread use of oxaliplatin in both adjuvant and first-line strategies for the treatment of $\mathrm{mCRC}$, irinotecan is commonly utilized in second-line or subsequent regimens. In a pilot study enrolling 14 patients progressing after treatment with oxaliplatin and irinotecan, bevacizumab plus FOLFIRI demonstrated good activity, achieving a response rate of $28.5 \%$ (including one complete response), median time to progression of 3.9 months (95\% CI: 2.0-8.7 months), and median OS of 10.9 months ( $95 \%$ CI: 9.6-12.1 months) [43]. In another series of 31 heavily pretreated patients, bevacizumab plus FOLFIRI or FOLFOX administered as second-, third-, or later-line chemotherapy achieved an ORR of $32.2 \%$ [44]. The response rate in FOLFIRI-treated patients was $36.9 \%$ (7/19), while it was $25 \%$ (3/12) in FOLFOX-treated patients. These data support the clinical utility of combination therapy with bevacizumab and FOLFIRI as second- or later-line treatment in $\mathrm{mCRC}$ and provide a rationale for randomized clinical evaluation of the regimen in this setting.

\section{Bevacizumab plus CAPIRI}

A range of clinical trials have evaluated bevacizumab in combination with capecitabine. These trials have demonstrated that CAPIRI plus bevacizumab is an effective regimen in mCRC, with comparable activity to CAPOX plus bevacizumab (tables 1, 2) [12, 13, 22, 23, 28]. The use of capecitabine with bevacizumab and irinotecan or oxaliplatin further expands the therapeutic options available for treating mCRC.

The AIO trial comparing bevacizumab plus CAPOX and bevacizumab plus CAPIRI is a randomized study in patients with chemonaïve mCRC and an ECOG PS $\leq 2$ [12]. The CAPIRI regimen incorporated $20 \%$ dose reduction compared with regimens used in previous trials reporting unacceptable gastrointestinal toxicity [10,34].

At the time of analysis, 247 patients were evaluated who had received a median of 8 and 9 cycles of CAPOX (127 patients) and CAPIRI (120 patients), respectively [12]. Treatment discontinuation has been documented for 222 patients and attributed to disease progression in 36\% (CAPOX/CAPIRI: 40\%/32\%), toxicity in 27\% (CAPOX/ CAPIRI: $39 \% / 16 \%)$ and the patient's decision in $17 \%$ (CAPOX/CAPIRI: 16\%/19\%). CAPOX and CAPIRI achieved similar response rates (53 and 55\%, respectively), similar tumor control rates ( 82 and $83 \%$, respective-
Table 3. Ongoing and planned trials of bevacizumab plus irinotecan in the first-line setting

\begin{tabular}{lccl}
\hline $\begin{array}{l}\text { Study (clinicaltrials.gov } \\
\text { identifier) }\end{array}$ & Phase & $\begin{array}{l}\text { Patients } \\
\text { planned }\end{array}$ \\
\hline NCT00469443 & III & 330 & $\begin{array}{l}\text { arm A: BEV + FOLFIRI } \\
\text { arm B: BEV + CAPIRI }\end{array}$ \\
\hline NCT00642603 & II & 280 & $\begin{array}{l}\text { arm A: BEV + CAPOX } \\
\text { arm B: BEV + CAPIRI }\end{array}$ \\
\hline NCT00433927 & III & 568 & $\begin{array}{l}\text { arm A: BEV + FOLFIRI } \\
\text { arm B: CET + FOLFIRI }\end{array}$ \\
\hline NCT00642577 & III & 210 & $\begin{array}{l}\text { arm A: BEV + FOLFIRI } \\
\text { arm B: FOLFIRI }\end{array}$ \\
\hline Planned & II & 150 & $\begin{array}{l}\text { arm A: BEV + FOLFIRI } \\
\text { arm B: BEV + CAPIRI }\end{array}$ \\
\hline NCT00483834 & II & 50 & BEV + CAPIRI \\
\hline NCT00719797 & III & 450 & $\begin{array}{l}\text { arm A: BEV + FOLFOXIRI } \\
\text { arm B: BEV + FOLFIRI }\end{array}$
\end{tabular}

$\mathrm{BEV}=$ Bevacizumab $; \mathrm{CET}=$ cetuximab FOLFIRI $=5-\mathrm{FU} / \mathrm{LV}$ + irinotecan.

ly) and 6-month PFS rates (76 and 84\%, respectively). Although median PFS was lower with CAPOX than CAPIRI (10.4 vs. 12.1 months), this difference was not statistically significant $(\mathrm{p}=0.27)$.

In accordance with the data for comparison of firstline combination with bevacizumab plus FOLFOX and FOLFIRI, these preliminary data support similar efficacy for CAPOX and CAPIRI. However, the tolerability profiles for CAPOX and CAPIRI differed substantially. While CAPOX and CAPIRI were associated with similar rates of grade $3 / 4$ diarrhea ( 21 and $16 \%$, respectively) and hand-foot syndrome (11 and $8 \%$, respectively), grade $3 / 4$ sensory neuropathy was substantially increased with CAPOX compared with CAPIRI (24 vs. 1\%) [12].

The data from the AIO trial therefore demonstrated that while both regimens are highly active and safe, the absence of neuropathy favors bevacizumab plus CAPIRI in first-line mCRC.

A formal comparison of CAPIRI plus bevacizumab versus FOLFIRI plus bevacizumab was carried out by the National Federation of French Cancer Centres within a randomized phase II trial (NCT00423696) [13]. This study included 145 patients and indicated comparable response rates (54 vs. 59\%) and identical durations for PFS (9 months) and OS (23 months) for both regimens. Also the toxicity profiles were manageable and comparable. 
Clinical adverse events observed in the CAPIRI and FOLFIRI arm such as grade $3-4$ neutropenia (18 vs. $27 \%$ ) and diarrhea (12 vs. $5 \%$ ) were considered low and compared well to previous reports.

\section{Duration of Bevacizumab Therapy}

The combination regimen of bevacizumab plus FOLFIRI or CAPIRI achieves remarkably consistent PFS in clinical trials (table 1). Generally, median PFS ranges from 11 to 13 months $[12,17,18,20,21,23]$ with median OS extending beyond 20 months, and despite being crosstrial comparisons, these data appear similar to the 10.6 and 20.3 months achieved for PFS and OS, respectively, in the pivotal trial with bevacizumab plus IFL [14]. Like the pivotal study with IFL, the clinical studies with FOLFIRI/CAPIRI and bevacizumab $(5 \mathrm{mg} / \mathrm{kg} / 2$ weeks or 7.5 $\mathrm{mg} / \mathrm{kg} / 3$ weeks) allowed treatment to disease progression. There is evidence to suggest that PFS with first-line chemotherapy for mCRC may be negatively impacted by reduced duration of bevacizumab therapy $[15,24]$. While inter-trial comparisons are undesirable, and data from randomized, controlled trials are limited, this observation, together with the manageable and noncumulative toxicity associated with bevacizumab, lend support to maintenance therapy with bevacizumab-based regimens. A further small, hypothesis-generating study has evaluated the use of maintenance bevacizumab in 34 patients receiving CAPIRI plus bevacizumab as first- or secondline treatment of mCRC [45]. The ORR was $47.1 \%$, with median PFS and OS of 8 and 14 months, respectively.

\section{Bevacizumab Treatment Beyond Disease Progression}

Bevacizumab beyond disease progression has been explored in the nonrandomized, observational BRiTE study $[26,27]$. The 1,953 patients registered to the study achieved median PFS and OS durations of 9.9 months (95\% CI: 9.5-10.3 months) and 22.9 months (95\% CI: 21.924.4 months), respectively. Notably, in the 1,445 patients with documented disease progression, bevacizumab beyond disease progression was significantly associated with a prolonged survival $(\mathrm{HR}=0.49 ; \mathrm{p}<0.001)$ on multivariate analysis [27]. Median OS was 12.6 months in the 253 patients that had no further treatment, 19.9 months in the 531 who had further treatment without bevacizumab and 31.8 months in the 642 patients who received further che- motherapy with bevacizumab. However, it should be noted that BRiTE is an uncontrolled, observational study and, as such, these data can only be considered to be suggestive.

As bevacizumab acts on stable endothelial cells, and not the frequently transforming cancer cells, there may be reduced potential for acquired resistance during the course of disease. However, there is some evidence that resistance can occur either by up-regulation of angiogenesis activators or bypassing vascular endothelial growth factor pathways to bevacizumab. There exists a need for prospective trials that assess the effect of continuing bevacizumab after progression of disease (with new chemotherapy combination partners). One such trial is a randomized, international, open-label phase III study, sponsored by Roche (NCT00700102).

\section{Bevacizumab in Patients with Oncogenic Mutations}

Various potentially prognostic or predictive markers have been proposed that identify patients with a likely poorer prognosis from those most likely to benefit from, or fail to respond to, a specific treatment. Recently, the well-established oncogene $K$-ras has received increasing attention as a marker due to evidence that demonstrates its negative prediction for the effectiveness of monoclonal antibodies targeting the epidermal growth factor receptor in patients carrying a gene mutation.

A retrospective analysis of data from 230 patients treated in the pivotal bevacizumab trial AVF2107g was carried out to determine whether mutations within $K$-ras, $b$-rafor p53 predict outcome in patients receiving bevacizumab $[46,47]$. The analysis suggested that bevacizumab provided survival benefit regardless of $K$-ras, $b$-raf or $p 53$ mutation status [46]. While a significantly higher response rate was observed with addition of bevacizumab only in K-ras wild-type patients ( 60.0 vs. $37.3 \%, \mathrm{p}=0.006)$, PFS and OS benefits were conferred in both $K$-ras mutant and wildtype patients (fig. 1) [47]. Notably, in a recent analysis of the PACCE trial, patients treated with irinotecan-based chemotherapy (FOLFIRI) and bevacizumab in the control arm achieved a median PFS that compares favorably to the majority of published data from controlled trials. The addition of the epidermal growth factor receptor antibody panitumumab to bevacizumab plus irinotecan-based chemotherapy in this trial resulted in shorter PFS compared with bevacizumab plus chemotherapy only, which was also observed regardless of patients' K-ras status (wildtype $K$-ras; 10.0 vs. 12.5 months, respectively: mutant $K$ ras; 8.3 vs. 11.9 months, respectively) [20]. 
Fig. 1. Bevacizumab improves PFS independent of $K$-ras mutation status [47]. Reproduced with permission of AlphaMed Press.

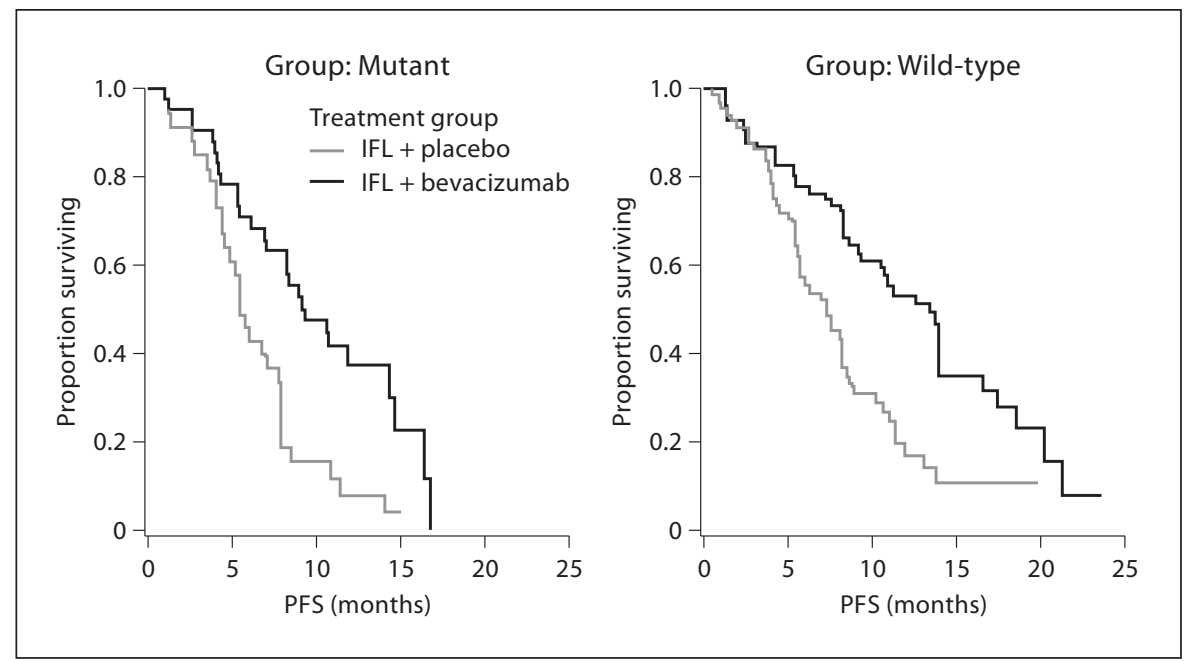

\section{Safety and Tolerability of Bevacizumab plus Irinotecan}

Bevacizumab has a consistent and well-defined safety profile across tumor types. Although bevacizumab is associated with an increase in some specific adverse events, including hypertension, proteinuria, arterial thromboembolic events, and gastrointestinal perforation (table 4), severe grade $3 / 4$ events are reported in low numbers for these toxicities and the majority of these events are generally mild to moderate in severity and manageable using standard therapies [48]. Irinotecan has historically been associated with high levels of diarrhea $[5,6,49]$, leading to some reservations concerning its use in first-line therapy. Thus, it is of interest to note that during the first period of the BICC-C study, FOLFIRI had the lowest incidence of grade $\geq 3$ diarrhea (13.9\%) of all the irinotecancontaining treatment arms. Further support for the use of irinotecan in a first-line setting came from the second phase of BICC-C during which the frequency of diarrhea did not increase following the addition of bevacizumab to FOLFIRI (10.7\%) [10]. Additionally, the incidence of grade $3 / 4$ diarrhea was shown to be comparable between patients receiving bevacizumab plus CAPOX (21\%) or reduced dose CAPIRI (16\%) during the AIO 0604 trial [12]. By reducing both the dose of capecitabine and irinotecan in this study, chemotherapy-related adverse events were minimized without compromising the efficacy of the CAPIRI regimen. Addition of bevacizumab to standard first-line chemotherapy does not significantly increase the incidence of chemotherapy-related toxicities compared with chemotherapy alone [14].

\section{Future Directions of Bevacizumab plus Irinotecan}

A number of ongoing or planned clinical trials will further evaluate the safety and efficacy of bevacizumab plus irinotecan-containing regimens for the first-line treatment of mCRC (table 3). The recent approval of bevacizumab in combination with all fluoropyrimidinebased standard chemotherapies as first and later lines of treatment for mCRC is likely to impact on current treatment guidelines for the disease. This label extension provides both physicians and patients with increased treatment options.

Several studies have investigated the possibility of combining different biological therapies that target different pathways critical to tumorigenesis. The phase II BOND-2 trial, for example, indicated that the combination of the epidermal growth factor receptor inhibitor cetuximab with bevacizumab and irinotecan was associated with clinical benefit [50, 51]. Similarly, median PFS and OS durations of 8.7 and 12.1 months, respectively, were reported in a recent Danish observational study in which bevacizumab was added after failure of third-line irinotecan plus cetuximab in 24 patients [52]. These findings have not, however, been borne out in phase III studies. In the CAIRO2 study, the addition of cetuximab to bevacizumab plus CAPOX produced a significant decrease in PFS compared with bevacizumab plus CAPOX alone (9.8 vs. 10.7 months, respectively; $\mathrm{p}=0.018$ ) [53]. Likewise, the addition of panitumumab to bevacizumab plus irinotecan-based chemotherapy in the PACCE study resulted in nominally lower PFS in the overall population (10.1 and 11.7 months for panitu- 
Table 4. Adverse events of special interest for bevacizumab in clinical and community-based trials

\begin{tabular}{|c|c|c|c|c|c|c|c|}
\hline \multirow[t]{2}{*}{ Study } & \multirow[t]{2}{*}{ Regimen } & \multicolumn{6}{|c|}{ Grade $\geq 3$ adverse events of special interest for bevacizumab, $\%$} \\
\hline & & hypertension & proteinuria & bleeding & ATE & VTE & GI perforation \\
\hline \multirow[t]{2}{*}{ AVF2107g [14] } & IFL + Placebo & 2.3 & 0.8 & 2.5 & \multicolumn{2}{|c|}{$16.2^{\mathrm{a}}$} & 0 \\
\hline & $\mathrm{IFL}+\mathrm{BEV}$ & 11 & 0.8 & 3.1 & \multicolumn{2}{|c|}{$19.4^{\mathrm{a}}$} & 1.5 \\
\hline AVIRI [24] & FOLFIRI + BEV & 5 & 2 & 4 & 4 & 18 & 2 \\
\hline MD Anderson [17] & FOLFIRI + BEV & 8 & 0 & 0 & - & 7 & 0 \\
\hline \multirow[t]{2}{*}{ BICC-C [10] } & $\mathrm{mIFL}+\mathrm{BEV}$ & 1.7 & - & - & - & - & - \\
\hline & FOLFIRI + BEV & 12.5 & - & - & - & - & - \\
\hline BEAT [25] & FOLFIRI + BEV & 3 & 1 & 3 & 1 & - & 2 \\
\hline \multirow[t]{2}{*}{ Moehler et al. [28] } & CAPIRI & - & 0 & - & 0 & 0 & - \\
\hline & CAPIRI + BEV & - & 3.4 & - & 0 & 0 & - \\
\hline \multirow[t]{2}{*}{ AIO 0604 [12] } & CAPIRI + BEV & 3 & - & 0 & - & - & 1 \\
\hline & CAPOX + BEV & 4 & - & 1 & - & - & 0 \\
\hline Ardalan et al. [21] & $\mathrm{IFL}+\mathrm{BEV}$ & - & - & - & 0 & 4.5 & 0 \\
\hline SICOG [29] & IRIFAFU + BEV & 1 & - & - & - & - & - \\
\hline Garcia Alfonso et al. [31] & CAPIRI + BEV & $2^{\mathrm{b}}$ & 0 & - & $2^{\mathrm{a}}$ & - & 0 \\
\hline \multirow[t]{2}{*}{ ACCORD [13] } & FOLFIRI + BEV & $8^{c}$ & 1 & 0 & 0 & 3 & 1 \\
\hline & CAPIRI + BEV & $3^{c}$ & 1 & 2 & 0 & 12 & 0 \\
\hline Welch et al. [23] & CAPIRI + BEV & 10 & - & - & - & 4 & 2 \\
\hline
\end{tabular}

$\mathrm{ATE}=$ Arterial thromboembolic event; BEV = bevacizumab; FOLFIRI = 5-FU/LV + irinotecan; GI = gastrointestinal; IRIFAFU = irinotecan, folinic acid, 5-FU; VTE = venous thromboembolic event.

${ }^{a}$ Thromboembolic events of any grade. ${ }^{b}$ Estimated from data presented graphically. ${ }^{c}$ Includes hypotension as well as hypertension.

mumab-containing and bevacizumab-only arms, respectively) and in both K-ras subgroups [20]. Therefore, there appears to be little advantage to combining either cetuximab or panitumumab with bevacizumab plus chemotherapy.

Another area of research is the identification of predictive markers of response to treatment. Possible markers include blood and tumor markers such as vascular endothelial growth factor and other growth factors, as well as polymorphisms in key genes. To date, however, no clear predictive biomarker for bevacizumab treatment has emerged. In addition, imaging techniques such as dynamic contrast-enhanced magnetic resonance imaging, computed tomography and positron emission tomography have the potential to provide a noninvasive way of evaluating biomarkers and predicting treatment response.

Bevacizumab plus Irinotecan in $\mathrm{mCRC}$

\section{Limitations of Data}

Although clinical trials demonstrate significant improvements in patient outcomes following the addition of bevacizumab to irinotecan, it is important to note that the available data are still somewhat limited. The only phase III data currently available are from the AVF $2107 \mathrm{~g}$ trial [14], while the majority of the other trials evaluating bevacizumab plus irinotecan are single arm only or do not have a randomized control arm [17, 25].

In addition, the two largest trials in terms of patient numbers, BEAT and BRiTE, are nonrandomized, observational studies [25-27]. However, considering these limitations, the unprecedented results from AVF2107g in conjunction with the wealth of available data support the use of bevacizumab in combination with irinotecan-containing regimens in patients with mCRC. Data from ongoing/upcoming trials will provide further insights into the important role of this regimen in this disease setting. 
Furthermore, it also needs to be determined whether permutations within given regimens reflect a justifiable need for large-scale controlled clinical trials in light of an increasingly complex and resource-limited environment.

\section{Conclusions}

Irinotecan-containing combinations have been an integral part of the treatment for mCRC for over a decade now, and they serve as excellent platforms for the addition of new molecular targeted therapies. The addition of bevacizumab to irinotecan improves outcomes in patients with mCRC, and its efficacy does not appear to be influenced by K-ras mutational status. Bevacizumab has a well-established safety profile and the toxicities associated with its use are usually mild in severity and easily manageable. Bevacizumab in combination with irinotecan-containing regimens is effective and should be considered an important therapy option for the treatment of mCRC.

\section{Acknowledgments}

Medical writing support by Helen Swainston of GardinerCaldwell Communications, Macclesfield, UK; this support was funded by F. Hoffmann-La Roche Ltd.

\section{References}

1 Ferlay J, Autier P, Boniol M, Heanue M, Colombet M, Boyle P: Estimates of the cancer incidence and mortality in Europe in 2006. Ann Oncol 2007;18:581-592.

2 Van Cutsem E, Nordlinger B, Adam R, Köhne $\mathrm{CH}$, Pozzo C, Poston G, Ychou M, Rougier $\mathrm{P}$, on behalf of the European Colorectal Metastases Treatment Group: Towards a pan-European consensus on the treatment of patients with colorectal liver metastases. Eur J Cancer 2006;42:2212-2221.

3 Rougier P, Van Cutsem E, Bajetta E, Niederle N, Possinger K, Labianca R, Navarro M, Morant R, Bleiberg H, Wils J, Awad L, Herait $\mathrm{P}$, Jacques C: Randomised trial of irinotecan versus fluorouracil by continuous infusion after fluorouracil failure in patients with metastatic colorectal cancer. Lancet 1998; 352:1407-1412.

4 Cunningham D, Pyrhonen S, James RD, Punt CJ, Hickish TF, Heikkila R, Johannesen TB, Starkhammar H, Topham CA, Awad L, Jacques C, Herait P: Randomised trial of irinotecan plus supportive care versus supportive care alone after fluorouracil failure for patients with metastatic colorectal cancer. Lancet 1998;352:1413-1418.

5 Douillard JY, Cunningham D, Roth AD, Navarro $M$, James RD, Karasek P, Jandik P, Iveson T, Carmichael J, Alakl M, Gruia G, Awad L, Rougier P: Irinotecan combined with fluorouracil compared with fluorouracil alone as first-line treatment for metastatic colorectal cancer: a multicentre randomised trial. Lancet 2000;355:1041-1047.

6 Saltz LB, Cox JV, Blanke C, Rosen LS, Fehrenbacher L, Moore MJ, Maroun JA, Ackland SP, Locker PK, Pirotta N, Elfring GL, Miller LL: Irinotecan plus fluorouracil and leucovorin for metastatic colorectal cancer. Irinotecan Study Group. N Engl J Med 2000; 343:905-914.
7 Van Cutsem E, Twelves C, Cassidy J, Allman D, Bajetta E, Boyer M, Bugat R, Findlay M, Frings S, Jahn M, McKendrick J, Osterwalder B, Perez-Manga G, Rosso R, Rougier P, Schmiegel WH, Seitz JF, Thompson P, Vieitez JM, Weitzel C, Harper P, on behalf of the Xeloda Colorectal Cancer Study Group: Oral capecitabine compared with intravenous fluorouracil plus leucovorin in patients with metastatic colorectal cancer: results of a large phase III study. J Clin Oncol 2001;19: 4097-4106.

8 Cassidy J, Twelves C, Van Cutsem E, Hoff P, Bajetta E, Boyer M, Bugat R, Burger U, Garin A, Graeven U, McKendric J, Maroun J, Marshall J, Osterwalder B, Pérez-Manga G, Rosso R, Rougier P, Schilsky RL, on behalf of the Capecitabine Colorectal Cancer Study Group: First-line oral capecitabine therapy in metastatic colorectal cancer: a favorable safety profile compared with intravenous 5-fluorouracil/leucovorin. Ann Oncol 2002; 13:566-575.

9 Twelves C, Boyer M, Findlay M, Cassidy J, Weitzel C, Barker C, Osterwalder B, Jamieson $\mathrm{C}$, Hieke $\mathrm{K}$, on behalf of the Xeloda Colorectal Cancer Study Group: Capecitabine (Xeloda) improves medical resource use compared with 5-fluorouracil plus leucovorin in a phase III trial conducted in patients with advanced colorectal carcinoma. Eur J Cancer 2001;37:597-604.

10 Fuchs CS, Marshall J, Mitchell E, Wierzbicki R, Ganju V, Jeffery M, Schulz J, Richards D, Soufi-Mahjoubi R, Wang B, Barrueco J: Randomized, controlled trial of irinotecan plus infusional, bolus, or oral fluoropyrimidines in first-line treatment of metastatic colorectal cancer: results from the BICC-C Study. J Clin Oncol 2007;25:4779-4786.
11 Koopman M, Antonini NF, Douma J, Wals J, Honkoop AH, Erdkamp FLG, de Jong RS, Rodenburg CJ, Vreugdenhil G, Loosveld OJL, van Bochove A, Sinnige HAM, Creemers GJM, Tesselaar MET, Slee PHTJ, Werter MJBP, Mol L, Dalesio O, Punt CJA: Sequential versus combination chemotherapy with capecitabine, irinotecan, and oxaliplatin in advanced colorectal cancer (CAIRO): a phase III randomised controlled trial. Lancet 2007;370:135-142.

12 Reinacher-Schick AC, Kubicka S, Freier W, Arnold D, Dietrich G, Geissler M, Hegewisch-Becker S, Graeven U, Schmoll H, Schmiegel W: Activity of the combination of bevacizumab (Bev) with capecitabine/irinotecan (CapIri/Bev) or capecitabine/oxaliplatin $(\mathrm{CapOx} / \mathrm{Bev})$ in advanced colorectal cancer (ACRC): a randomized phase II study of the AIO Colorectal Study Group (AIO trial 0604) (abstract 4030). J Clin Oncol 2008; 26(suppl):185s.

13 Ducreux M, Adenis A, Mendiboure J, François E, Boucher E, Chauffert B, Ychou M, Pierga J, Montoto-Grillot C, Conroy T: Efficacy and safety of bevacizumab (BEV)-based combination regimens in patients with metastatic colorectal cancer (mCRC): randomized phase II study of BEV + FOLFIRI versus BEV + XELIRI (FNCLCC ACCORD 13/0503 study) (abstract 4086). J Clin Oncol 2009; 27(suppl):189s.

14 Hurwitz H, Fehrenbacher L, Novotny W, Cartwright T, Hainsworth J, Heim W, Berlin J, Baron A, Griffing S, Holmgren E, Ferrara N, Fyfe G, Rogers B, Ross R, Kabbinavar F: Bevacizumab plus irinotecan, fluorouracil, and leucovorin for metastatic colorectal cancer. N Engl J Med 2004;350: 2335-2342. 
15 Saltz LB, Clarke S, Diaz-Rubio E, Scheithauer W, Figer A, Wong R, Koski S, Lichinitser M, Yang TS, Rivera F, Couture F, Sirzén F, Cassidy J: Bevacizumab in combination with oxaliplatin-based chemotherapy as first-line therapy in metastatic colorectal cancer: a randomized phase III study. J Clin Oncol 2008;26:2013-2019.

16 Cao Y, Tan A, Gao F, Liu L, Liao C, Mo Z: A meta-analysis of randomized controlled trials comparing chemotherapy plus bevacizumab with chemotherapy alone in metastatic colorectal cancer. Int J Colorectal Dis 2009;24:677-685.

17 Kopetz S, Glover Y, Eng C, Wolff RA, Chang DZ, Adinin RB, Morris J, Abbruzzese JL, Hoff PM: Phase II study of infusional 5-fluorouracil, leucovorin, and irinotecan (FOLFIRI) plus bevacizumab as first-line treatment for metastatic colorectal cancer (abstract 4089). J Clin Oncol 2007;25(suppl): $185 \mathrm{~s}$.

18 Fuchs CS, Marshall J, Barrueco J: Randomized, controlled trial of irinotecan plus infusional, bolus, or oral fluoropyrimidines in first-line treatment of metastatic colorectal cancer: updated results from the BICC-C study. J Clin Oncol 2008;26:689-690.

19 Falcone A, Masi G, Loupakis F, Vasile E, Ciarlo A, Cavaciocchi D, Amoroso D, Puglisi M, Fea E, Brunettiet I: FOLFOXIRI (irinotecan, oxaliplatin, and infusional 5FU/LV) in combination with bevacizumab (BV) in the first-line treatment of metastatic colorectal cancer (mCRC): a phase II study by the G.O.N.O. group (abstract 4031). J Clin Oncol 2008;26(suppl):185s.

20 Hecht JR, Mitchell E, Chidiac T, Scroggin C, Hagenstad C, Spigel D, Marshall J, Cohn A, McCollum D, Stella P, Deeter R, Shahin S, Amado RG: A randomized phase IIIB trial of chemotherapy, bevacizumab, and panitumumab compared with chemotherapy and bevacizumab alone for metastatic colorectal cancer. J Clin Oncol 2009;27:672-680.

21 Ardalan B, Feagans M, Mezentsev D, Jones C, Subbarayan PR, Walker G, Sapp M, Stephenson K, Ness J, Franceschi D, Livingstone A: Phase II study of bevacizumab (B), irinotecan (I), high-dose 24-hour continuous intravenous infusion of floxuridine $(\mathrm{F})$ and leucovorin (L) in patients with previously untreated metastatic colon cancer (B-IFL) (abstract 489). 2009 Gastrointestinal Cancers Symp, San Francisco, January 2009. Available at: http://www.asco.org. Accessed February 10, 2009.

22 Vieitez J, Fonseca P, Crespo G, Berros J, Fernández de Sanmamed M, Muriel C, Izquierdo M, Pardo P, Esteban E, Lacave A: Results of a phase II study of capecitabine, CPT-11 (CAPIRI) and bevacizumab in chemotherapy-naïve stage IV colorectal cancer patients (abstract 404). 2009 Gastrointestinal Cancers Symp, San Francisco, January 2009. Available at: http://www.asco.org. Accessed February 10, 2009.
23 Welch S, Krzyzanowska M, Moore MJ, Mackay H, Knox JJ, Feld R, Petronis J, Blattler C, Wang L, Chen E: Phase II study of capecitabine, irinotecan, and bevacizumab (XELIRI-A) in patients (pts) with previously untreated metastatic colorectal cancer (mCRC) (abstract 475). 2009 Gastrointestinal Cancers Symp, San Francisco, January 2009. Available at: http://www.asco.org. Accessed February 11, 2009.

24 Sobrero A, Ackland S, Clarke S, Perez-Carrión $R$, Chiara S, Gapski J, Mainwaring $P$, Langer B, Young S, on behalf of AVIRI Trial Investigators: Phase IV study of bevacizumab in combination with infusional fluorouracil, leucovorin and irinotecan (FOLFIRI) in first-line metastatic colorectal cancer. Oncology 2009;77:113-119.

25 Van Cutsem E, RiveraF, BerryS, Kretzschmar A, Michael M, DiBartolomeo M, Mazier MA, Canon JL, Georgoulias V, Peeters M, Bridgewater J, Cunningham D: Safety and efficacy of first-line bevacizumab with FOLFOX, XELOX, FOLFIRI and fluoropyrimidines in metastatic colorectal cancer: the BEAT study. Ann Oncol 2009;20:1842-1847.

26 Kozloff M, Yood MU, Berlin J, Flynn PJ, Kabbinavar FF, Purdie DM, Ashby MA, Dong W, Sugrue MM, Grothey A, for the investigators of the BRiTE study: Clinical outcomes associated with bevacizumab-containing treatment of metastatic colorectal cancer: the BRiTE observational cohort study. Oncologist 2009; 14:862-870.

27 Grothey A, Sugrue MM, Purdie DM, Dong W, Sargent D, Hedrick E, Kozloff M: Bevacizumab beyond first progression is associated with prolonged overall survival in metastatic colorectal cancer: results from a large observational cohort study (BRiTE). J Clin Oncol 2008;262:5326-5334.

28 Moehler M, Sprinzl MF, Abdelfatah M, Schimanski CC, Adami B, Godderz W, Majer K, Flieger D, Teufel A, Siebler J, Hoehler T, Galle PR, Kanzler S: Capecitabine and irinotecan with and without bevacizumab for advanced colorectal cancer patients. World J Gastroenterol 2009;15:449-456.

29 Comella P, Massidda B, Natale D, Filippelli G, Farris A, Condemi G, Palmeri S, Tafuto S, Vessia G, Barberis G: Bevacizumab (Bev), irinotecan (IRI), folinic acid (FA), and 5-fluorouracil (FU) every 2 weeks (BIFF regimen) as first-line treatment for metastatic colorectal cancer (MCRC) patients (pts): the SICOG experience (abstract e15067). J Clin Oncol 2009. Available at: http://www.asco.org. Accessed June 28, 2010.

30 Degirmenci M, Karaca B, Gorumlu G, Durusoy R, Demir Piskin G, Bozkurt MT, Cirak Y, Tunali D, Karabulut B, Sanli UA, Uslu R: Efficacy and safety of bevacizumab plus capecitabine and irinotecan regimen for metastatic colorectal cancer. Med Oncol 2009, E-pub ahead of print.
31 Garcia Alfonso P, Muñoz Martín A, Gonzalez del Val R, Parkam Khosravi S, Izarzugaza Perón Y, Arranz Cozar J, Cabezón Gutierrez L, Márquez-Rodas I, Soria Lobelle A, Pérez Manga G: Efficacy and safety of the first-line treatment with a combination of bevacizumab and biweekly XELIRI in metastatic colorectal cancer without previous treatment (abstract 431). 2009 Gastrointestinal Cancers Symp, San Francisco, January 2009. Available at: http://www.asco.org. Accessed February 10, 2009.

32 Grothey A, Hedrick EE, Mass RD, Sarkar S, Suzuki S, Ramanathan RK, Hurwitz HI, Goldberg RM, Sargent DJ: Response-independent survival benefit in metastatic colorectal cancer: a comparative analysis of N9741 and AVF2107. J Clin Oncol 2008;26:183-189.

33 Seifert P, Baker LH, Reed ML, Vaitkevicius VK: Comparison of continuously infused 5 -fluorouracil with bolus injection in treatment of patients with colorectal adenocarcinoma. Cancer 1975;36:123-128.

34 Rothenberg ML, Meropol NJ, Poplin EA, Van Cutsem E, Wadler S: Mortality associated with irinotecan plus bolus fluorouracil/ leucovorin: summary findings of an independent panel. J Clin Oncol 2001;19:38013807.

35 Giantonio BJ, Levy DE, O’Dwyer PJ, Meropol NJ, Catalano PJ, Benson AB 3rd: A phase II study of high-dose bevacizumab in combination with irinotecan, 5-fluorouracil, leucovorin, as initial therapy for advanced colorectal cancer: results from the eastern cooperative oncology group study E2200. Ann Oncol 2006;17:1399-1403.

36 Tournigand C, Andre T, Achille E, Lledo G, Flesh M, Mery-Mignard D, Quinaux E, Couteau C, Buyse M, Ganem G, Landi B, Colin P, Louvet C, de Gramont A: FOLFIRI followed by FOLFOX6 or the reverse sequence in advanced colorectal cancer: a randomized GERCOR study. J Clin Oncol 2004;22:229237.

37 Jackson NA, Barrueco J, Soufi-Mahjoubi R, Marshall J, Mitchell E, Zhang X, Meyerhardt $\mathrm{J}$ : Comparing safety and efficacy of first-line irinotecan/fluoropyrimidine combinations in elderly versus nonelderly patients with metastatic colorectal cancer: findings from the bolus, infusional or capecitabine with camptostar-celecoxib study. Cancer 2009; 115:2617-2629.

38 Metges J, Grudé F, Faroux R, Achour N, Douillard J, Klein V, Ramée J, Etienne P, Ganem G, Riche C, Gamelin E: FOLFIRI bevacizumab in unresectable metastatic colorectal cancer (UMCC) in true life, feasibile in elderly patients (EP): results of the cohort from OMIT Bretagne-Pays de Loire (abstract 398). 2009 Gastrointestinal Cancers Symp, San Francisco, January 2009. Available at: http://www.asco.org. Accessed February 11, 2009. 
39 Fyfe GA, Hurwitz H, Fehrenbacher L, Cartwright T, Hainsworth J, Heim W, Berlin J, Kabbinavar F, Holmgren E, Novotny W: Bevacizumab plus irinotecan/5-FU/leucovorin for treatment of metastatic colorectal cancer results in survival benefit in all pre-specified patient subgroups (abstract 3617). J Clin Oncol 2004;22(suppl):274s

40 Kozloff M, Sugrue MM, Berlin J, Flynn RJ, Kabbinavar F, Sargent D, Purdie DM, Dong W, Grothey A: Safety and effectiveness of bevacizumab and chemotherapy in elderly patients with mCRC: results from the BRiTE observational cohort study (abstract 454). 2008 Gastrointestinal Cancers Symp, Orlando, January 2008. Available at: http://www. asco.org. Accessed June 29, 2010.

41 Santomaggio A, Ricevuto E, Cannita K, Bruera G, Tudini M, Lanfiuti Baldi P, Mancini M, Porzio G, Marchetti P, Ficorella C: 'Poker' schedule of weekly alternating 5 -fluorouracil, irinotecan, bevacizumab, and oxaliplatin (FIR-B/FOX) in advanced colorectal cancer: a phase II study (abstract 4125). J Clin Oncol 2009;27(suppl):199s.

42 Falcone A: Combination chemotherapy and bevacizumab as first-line therapy in treating patients with metastatic colorectal cancer. Available at: http://www.clinicaltrials.gov. Accessed October 23, 2008.

43 Kwon HC, Oh SY, Lee S, Kim SH, Kim HJ: Bevacizumab plus infusional 5-fluorouracil, leucovorin and irinotecan for advanced colorectal cancer that progressed after oxaliplatin and irinotecan chemotherapy: a pilot study. World J Gastroenterol 2007;13:62316235.
44 Lièvre A, Samalin E, Mitry E, Assenat E, Boyer-Gestin C, Lepère C, Bachet JB, Portales F, Vaillant JN, Ychou M, Rougier P: Bevacizumab plus FOLFIRI or FOLFOX in chemotherapy-refractory patients with metastatic colorectal cancer: a retrospective study. BMC Cancer 2009;9:347.

45 Ardavanis A, Kountourakis P, Mantzaris I, Malliou S, Doufexis D, Sykoutri D, Fragos I, Rigatos G: Bevacizumab added to the irinotecan and capecitabine combination for advanced colorectal cancer: a well-tolerated active and convenient regimen. Anticancer Res 2008;28:3087-3092.

46 Ince WL, Jubb AM, Holden SN, Holmgren EB, Tobin P, Sridhar M, Hurwitz HI, Kabbinavar F, Novotny WF, Hillan KJ, Koeppen $\mathrm{H}$ : Association of K-ras, b-raf, and p53 status with the treatment effect of bevacizumab. J Natl Cancer Inst 2005;97:981-989.

47 Hurwitz H, Yi J, Ince W, Novotny WF, Rosen $\mathrm{O}$ : The clinical benefit of bevacizumab in metastatic colorectal cancer is independent of k-ras mutation status: analysis of a phase III study of bevacizumab with chemotherapy in previously untreated metastatic colorectal cancer. Oncologist 2009;14:2228

48 F. Hoffmann-La Roche Ltd.: Avastin (bevacizumab) Summary of Product Characteristics 2010. Available at: http://www.emea. europa.eu/humandocs/Humans/EPAR/ avastin/avastin.htm 2008. Accessed June 29, 2010.

49 Saliba F, Hagipantelli R, Misset JL, Bastian G, Vassal G, Bonnay M, Herait P, Cote C, Mahjoubi M, Mignard D, Cvitkovic E: Pathophysiology and therapy of irinotecan-induced delayed-onset diarrhea in patients with advanced colorectal cancer: a prospective assessment. J Clin Oncol 1998;16:2745-2751.
50 Saltz LB, Lenz HJ, Kindler HL, Hochster HS, Wadler S, Hoff PM, Kemeny NE, Hollywood EM, Gonen M, Quinones M, Morse M, Chen HX: Randomized phase II trial of cetuximab, bevacizumab, and irinotecan compared with cetuximab and bevacizumab alone in irinotecan-refractory colorectal cancer: the BOND-2 study. J Clin Oncol 2007;25:4557-4561.

51 Cunningham D, Humblet Y, Siena S, Khayat D, Bleiberg H, Santoro A, Bets D, Mueser M, Harstrick A, Verslype C, Chau I, Van Cutsem E: Cetuximab monotherapy and cetuximab plus irinotecan in irinotecan-refractory metastatic colorectal cancer. N Engl J Med 2004;351:337-345.

52 Skougaard K, Nielsen D, Pfeiffer P, Joergensen T, Bjerregaard JK, Jensen BV: Bevacizumab in combination with cetuximab and irinotecan (BCI) after failure of cetuximab and irinotecan (CI) in patients with metastatic colorectal cancer (mCRC) (abstract 482). 2009 Gastrointestinal Cancers Symp, San Francisco, January 2009. Available at: http:// www.asco.org. Accessed February 11, 2009.

53 Punt CJ, Tol J, Rodenburg CJ, Cats A, Creemers G, Schrama JG, Erdkamp FL, Vos A, Mol L, Antonin NF: Randomized phase III study of capecitabine, oxaliplatin, and bevacizumab with or without cetuximab in advanced colorectal cancer (ACC), the CAIRO2 study of the Dutch Colorectal Cancer Group (DCCG) (abstract LBA4011). J Clin Oncol 2008;26(suppl):1008s. 